\title{
Angiotensin II stimulates melanogenesis via the protein kinase $\mathbf{C}$ pathway
}

\author{
LI-HONG LIU ${ }^{1,2}$, XIN FAN $^{2}$, ZHI-KUAN XIA ${ }^{2}$, XU-XI AN ${ }^{2}$ and RONG-YA YANG ${ }^{2}$ \\ ${ }^{1}$ Graduate School, The Third Military Medical University, Chongqing 400038; ${ }^{2}$ Department of Dermatology, \\ General Hospital of Beijing Military Region of PLA, Beijing 100125, P.R. China
}

Received January 21, 2015; Accepted June 16, 2015

DOI: $10.3892 /$ etm.2015.2682

\begin{abstract}
Melanogenesis is a physiological process that results in the synthesis of melanin pigments, which serve a crucial function in hyperpigmentation. The aim of the present study was to determine the effects of angiotensin II (Ang II) on melanogenesis and to elucidate the molecular events of Ang II-induced melanogenesis. Experiments were performed on human melanocytes to elucidate the pigmenting effect of Ang II and the underlying mechanisms. The elements involved in melanogenesis, including melanin content, tyrosinase (TYR) activity, and microphthalmia-associated transcription factor (MITF) and TYR expression at the mRNA and protein levels were evaluated. Melanin content and TYR activity increased in response to Ang II treatment in a concentration-dependent manner. MITF and TYR mRNA and protein expression levels were increased significantly in response to Ang II in a concentration-dependent manner. The Ang II-induced increase in melanin synthesis was reduced significantly in response to co-treatment with Ro-32-0432, a protein kinase C (PKC) inhibitor, whereas co-treatment with $\mathrm{H}-89$, a PKA inhibitor, did not attenuate the Ang II-induced increase in melanin levels. These results suggest that PKC is required for Ang II-induced pigmentation in human melanocytes and that the mechanism involves the PKC pathway and MITF upregulation.
\end{abstract}

\section{Introduction}

Hyperpigmentation is commonly observed in humans following skin damage and during the healing response; it includes post-inflammatory hyperpigmentation after burns, wounds or laser surgery. Hyperpigmentation is a major concern for the majority of people it affects as it induces significant cosmetic problems that may affect quality of life. However, the

Correspondence to: Professor Rong-Ya Yang, Department of Dermatology, General Hospital of Beijing Military Region of PLA, 5 Namencang Street, Beijing 100125, P.R. China

E-mail: liulihongzjk@sina.com

Key words: melanogenesis, angiotensin II, tyrosinase, microphthalmia-associated transcription factor, protein kinase $\mathrm{C}$ treatment of hyperpigmentation remains a challenge and the results are discouraging. Recently, a number of studies have focused on pigment cells and wound healing (1-4); however, knowledge of skin repigmentation following cutaneous injury remains sparse.

The role of angiotensin II (Ang II) in the control of systemic blood pressure and volume homeostasis is well known and has been extensively studied $(5,6)$. Recently, it was suggested that Ang II is also involved in the healing of skin wounds. It has been proposed that exogenously administered Ang II is a potent accelerator of cutaneous wound repair $(7,8)$. These reports indicated that the topical administration of Ang II accelerated skin wound healing by stimulating dermal repair, including angiogenesis and epidermal repair, in vivo. Furthermore, studies have demonstrated that Ang II is angiogenic and modulates the proliferation, growth factor production and chemotaxis of numerous cell types (8-10). Steckelings et al (11) reported that human skin expresses Ang II type 1 (AT1) and type 2 (AT2) receptors, and that AT1 and AT2 receptor expression is markedly enhanced within the epidermal and dermal areas of scar tissue (12). A previous study reported that inhibiting the AT1 receptor limited murine melanoma growth (13). In addition, Steckelings et al (11) detected the expression of AT1 mRNA in cultured primary melanocytes, suggesting its possible function in melanocytes.

Pigment production is complex and controlled by numerous extrinsic and intrinsic factors involved in melanin synthesis and melanocyte transport. Melanogenesis is controlled by complex regulatory mechanisms. The genes encoding tyrosinase (TYR) and TYR-related proteins contain common transcription initiation sites, particularly microphthalmia-associated transcription factor (MITF) binding sites. MITF serves a crucial function in the transcriptional regulation of melanogenesis (14). The intracellular signal transduction pathways of cyclic adenosine monophosphate (cAMP), protein kinase $\mathrm{C}$ (PKC) and nitrogen oxide (NO) are involved in the regulation of melanogenesis (15). A number of previous studies have indicated that $\mathrm{CAMP}$ and $\mathrm{PKC}$ are involved in key signal transduction pathways that participate in the regulation of melanogenesis (16-18). In the cardiovascular system, Ang II shares certain subcellular pathways with the following pathways, widely interacting with them: AT1, PKC, and $\mathrm{Na}^{+} / \mathrm{H}^{+}$ exchange (NHE) (19), endothelin-1 (ET-1) and NO (20) and cAMP (21). The present study was based on the hypothesis 
that Ang II may be able to modulate melanocyte melanogenesis via different pathways. To clarify this issue, the effects of Ang II on human melanocyte melanogenesis were investigated in order to elucidate the possible mechanisms involved.

\section{Materials and methods}

Compounds and drugs. Mouse polyclonal antibodies against MITF (sc-56725) and TYR (sc-20035), and horseradish peroxidase (HRP)-conjugated goat anti-rabbit or anti-mouse antibodies (sc-2005) were purchased from Santa Cruz Biotechnology, Inc. (Santa Cruz, CA, USA). A protein quantification kit and agarose were purchased from Bio-Rad Laboratories, Inc. (Hercules, CA, USA). PCR Master Mix was purchased from Promega Corporation (Madison, WI, USA). Phosphate-buffered saline (PBS), M254 medium and human melanocyte growth supplements were purchased from Cascade Biologics, Inc. (Mansfield, UK). Fetal bovine serum (FBS) and an RNeasy Mini kit were from Qiagen, Inc. (Valencia, CA, USA). Ang II, H-89 (PKA inhibitor) and Ro-32-0432 (PKC inhibitor) were from EMD Millipore (Billerica, MA, USA). L-3,4-dihydroxyphenylalanine (L-DOPA), EDTA, glycine, sodium dodecyl sulfate (SDS) and Tris were purchased from Sigma-Aldrich (St. Louis, MO, USA).

Melanocyte culture. The present study was ethically approved by the General Hospital of Beijing Military Region of PLA. Primary melanocyte cultures were established as follows: Normal melanocytes were isolated from the epidermis of human foreskins. Skin grafts were cut into $5 \times 5 \mathrm{~mm}$ pieces and incubated with trypsin-EDTA (0.25\% trypsin, $0.02 \%$ EDTA) at $4^{\circ} \mathrm{C}$ overnight. Trypsin activity was required to separate the epidermis from the dermis, via intercellular detachment. The next day, trypsin activity was neutralized by adding FBS in a 1:1 ratio and replacing it with PBS solution. The epidermis was separated from the dermis using sterile forceps. The specimens were pipetted thoroughly to separate the cells and form cell-rich suspensions. The solid waste tissue was removed and the suspension was centrifuged at $1,000 \mathrm{x} \mathrm{g}$ for 5 min. Then, melanocytes were selectively grown in M254 medium containing human melanocyte growth supplements. The cell number was adjusted to $2.5 \times 10^{4}$ cells $/ \mathrm{cm}^{2}$. Cultures were maintained at $37^{\circ} \mathrm{C}$ in a humidified $95 \%$ air and $5 \% \mathrm{CO}_{2}$ atmosphere. The medium was changed at 2-3-day intervals, and the cultures were routinely examined for contamination and cell outgrowth. Cells were split at confluence using 5-min trypsin treatment at room temperature. Subculturing was conducted once a week and experiments were carried out from passages II-IV.

Treatment with Ang II alone or in combination with H-89 or Ro-32-0432. Confluent cells were plated at subconfluent densities $\left(2 \times 10^{5}\right.$ cells $)$ in 6 -well plates and grown for 4 days until confluent. Then, they were treated with different concentrations $(0.01,0.1,1,10$ and $100 \mathrm{nM})$ of Ang II for $24 \mathrm{~h}$. In some experiments, the cells were incubated with $1 \mu \mathrm{M} \mathrm{H}-89$ or Ro-32-0432 for 60 min prior to stimulation with $100 \mathrm{nM}$ Ang II. The culture medium was removed and the cells were washed twice with PBS. Then, fresh assay medium supplemented with $0.1 \%$ FBS was added for $24 \mathrm{~h}$. Subsequently, the melanin content assay was performed, and TYR activity and melanin content were determined. Cell homogenates and supernatants were collected for RNA extraction using the RNeasy Mini kit and for protein quantification using the kit from Bio-Rad Laboratories, Inc. by a procedure based on the Bradford method.

TYR activity assay. Melanocytes were treated with Ang II for the indicated durations, and then washed with ice-cold $1 \mathrm{X}$ PBS. Lysis buffer, containing $150 \mu 11 \%$ Triton X-100 in $0.1 \mathrm{M}$ phosphate buffer, was added to each 6-well plate. Cells were scraped and transferred to a $1.5-\mathrm{ml}$ tube, lysed using 3-5 freeze-thaw cycles in liquid nitrogen and centrifuged at $15,000 \times \mathrm{g}$ for $5-10 \mathrm{~min}$ at $4^{\circ} \mathrm{C}$. Samples $(300-500 \mu \mathrm{g} / 80 \mu \mathrm{l})$ were transferred to a new 96-well plate on ice. L-DOPA $(20 \mu 1$, $5 \mathrm{mM}$ ) was added to each well, the plate was incubated at $37^{\circ} \mathrm{C}$ for $1 \mathrm{~h}$ and the absorbance was measured at $475 \mathrm{~nm}$ using a DU-70 spectrophotometer (Beckman Coulter, Brea, CA, USA).

Melanin content assay. Melanin content was determined using a standard procedure (22). Cells were lysed with $200 \mu 11 \mathrm{~N}$ $\mathrm{NaOH}$ and pipetted repeatedly to homogenize them. Then, the cell extract was transferred to 96-well plates. Relative melanin content was determined by absorbance at $405 \mathrm{~nm}$ using a Synergy H1MF enzyme-linked immunosorbent assay plate reader (BioTek, Winooski, VT, USA).

Reverse transcription-quantitative polymerase chain reaction $(R T-q P C R)$. Total RNA extraction and reverse transcriptase reaction were performed as described previously (23). The MITF and TYR mRNA expression levels were evaluated using RT-qPCR. Total RNA was extracted at the indicated time points using a TRIzol kit (Invitrogen Life Technologies, Carlsbad, CA, USA) and reverse-transcribed using an RT kit (Toyobo Co., Ltd., Osaka, Japan). Semi-quantitative PCR was performed using PCR Master Mix and primers for MITF and TYR; Table I lists the primer sequences and amplicon size. PCR was performed using a touchdown protocol as previously described (24). Briefly, touchdown PCR was performed using the following program: 1 cycle at $94^{\circ} \mathrm{C}$ for $2 \mathrm{~min}, 12$ cycles at $92^{\circ} \mathrm{C}$ for $20 \mathrm{sec}, 68^{\circ} \mathrm{C}$ for $30 \mathrm{sec}$ and $70^{\circ} \mathrm{C}$ for $45 \mathrm{sec}$ with a reduction of $1^{\circ} \mathrm{C}$ per cycle, and 22 cycles at $92^{\circ} \mathrm{C}$ for $20 \mathrm{sec}$, $55^{\circ} \mathrm{C}$ for $30 \mathrm{sec}$ and $70^{\circ} \mathrm{C}$ for $45 \mathrm{sec}$. PCR products were separated by electrophoresis on $2 \%$ agarose gels and visualized with ethidium bromide staining. PCR band intensity was expressed as the relative intensity against $\beta$-actin.

Western blot analysis. MITF and TYR protein expression was evaluated using western blot analysis. Isolated human foreskin sheets were homogenized using a pestle in lysis buffer and centrifuged for $30 \mathrm{~min}$ at $15,000 \mathrm{x} \mathrm{g}$ at $4^{\circ} \mathrm{C}$. The supernatant was collected and protein concentration determined using the protein quantification kit, based on the bicinchoninic acid method. Proteins $(20 \mu \mathrm{g})$ were denatured with SDS sample buffer, boiled for $5 \mathrm{~min}$ and separated in 10-12\% polyacrylamide gels (Novex; Life Technologies, Grand Island, NY, USA). Following electrophoresis, proteins were transferred in $1 \mathrm{X}$ transfer buffer $(25 \mathrm{mM}$ Tris, $192 \mathrm{mM}$ glycine, $0.1 \%$ SDS, $20 \%$ methanol, $\mathrm{pH} 8.4$ ) to a $0.45-\mu \mathrm{m}$ Immobilon-P polyvinylidene difluoride membrane (EMD Millipore) in a 
Table I. Primers used in reverse transcription-quantitative polymase chain reaction.

\begin{tabular}{llc}
\hline Primer & \multicolumn{1}{c}{ Sequence (5'-3') } & Size (bp) \\
\hline MITF & $\begin{array}{l}\text { F: CACAACCTGATTGAACGAAG } \\
\text { R: GTGGATGGAATAAGGGAAAG }\end{array}$ & 284 \\
TYR & $\begin{array}{l}\text { F: ACGATGTGGACGAGTGT } \\
\text { R: CAGAGGCAGGTGAAGGT }\end{array}$ & 133 \\
\multirow{3}{*}{-actin } & $\begin{array}{l}\text { F: ATCATGTTTGAGACCTTCAACA } \\
\text { R: CATCTCTTGCTCGAAGTCCA }\end{array}$ & 318 \\
\hline
\end{tabular}

MITF, microphthalmia-associated transcription factor; TYR, tyrosinase; $\mathrm{F}$, forward; $\mathrm{R}$, reverse.

Mini PROTEAN II Transfer Cell (Bio-Rad Laboratories, Inc.) set at a constant voltage of $120 \mathrm{mV}$ for $2 \mathrm{~h}$. Membranes were blocked in 5\% non-fat dry milk in Tris-buffered saline (TBS) solution for $\geq 1 \mathrm{~h}$ at room temperature. Blots were incubated overnight at $4{ }^{\circ} \mathrm{C}$ with polyclonal mouse anti-MITF $(1: 1,1000)$ or anti-TYR $(1: 1,000)$ antibodies. Membranes were washed three times with TBS containing 1\% Triton X-100 (TBS-T), incubated with HRP-conjugated goat anti-mouse antibodies $(1: 2,000)$ for $2 \mathrm{~h}$ at room temperature, then washed 4 times with TBS-T. Immunoreactive bands were visualized by exposing membrane blots to a chemiluminescent solution and the proteins were visualized on X-ray film using an enhanced chemiluminescence western blot detection system (Pierce Biotechnology, Inc., Rockford, IL, USA). Three independent experiments were performed in triplicate.

Statistical analysis. Statistical analysis was performed using SPSS software, version 14.0 (SPSS Inc., Chicago, IL, USA). Data are presented as the mean \pm standard error. Statistical analysis between groups was performed using analysis of variance. $\mathrm{P}<0.05$ was considered to indicate a statistically significant difference.

\section{Results}

Ang II regulates TYR activity and melanin content. TYR activity and melanin content increased significantly in a dose-dependent manner following treatment with Ang II (Fig. 1). Significant increases in TYR activity and melanin content were observed in the cells incubated with 0.1-100 nM Ang II for $24 \mathrm{~h}$. The maximal increases were achieved with $100 \mathrm{nM}$ Ang II $(\mathrm{P}<0.01)$.

Ang II regulates MITF and TYR $m R N A$ and protein expression. MITF is the master regulator of melanogenesis, regulating the expression of TYR $(7,25)$, the key regulatory enzyme in melanin biosynthesis (26). Investigation of the effects of Ang II on MITF and TYR mRNA and protein expression levels in human melanocytes by RT-qPCR and western blot analysis revealed that there was a significant increase in transcription following a 24-h incubation with higher concentrations of Ang II (0.1-100 nM; Fig. 2A). A maximal increase was achieved with $100 \mathrm{nM}$ Ang II (P<0.01; Fig. 2B).

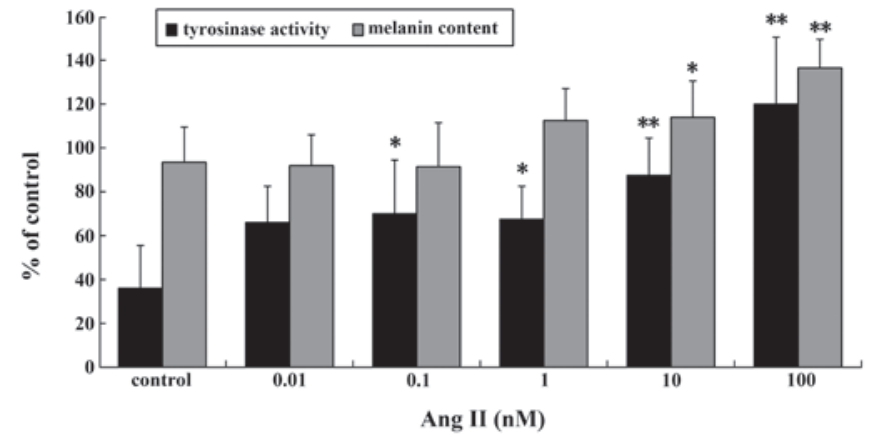

Figure 1. Tyrosinase activity and melanin content following Ang II treatment. Results are expressed as the mean \pm standard error. ${ }^{*} \mathrm{P}<0.05$ and ${ }^{* *} \mathrm{P}<0.01$ vs. control. Ang II, angiotensin II.

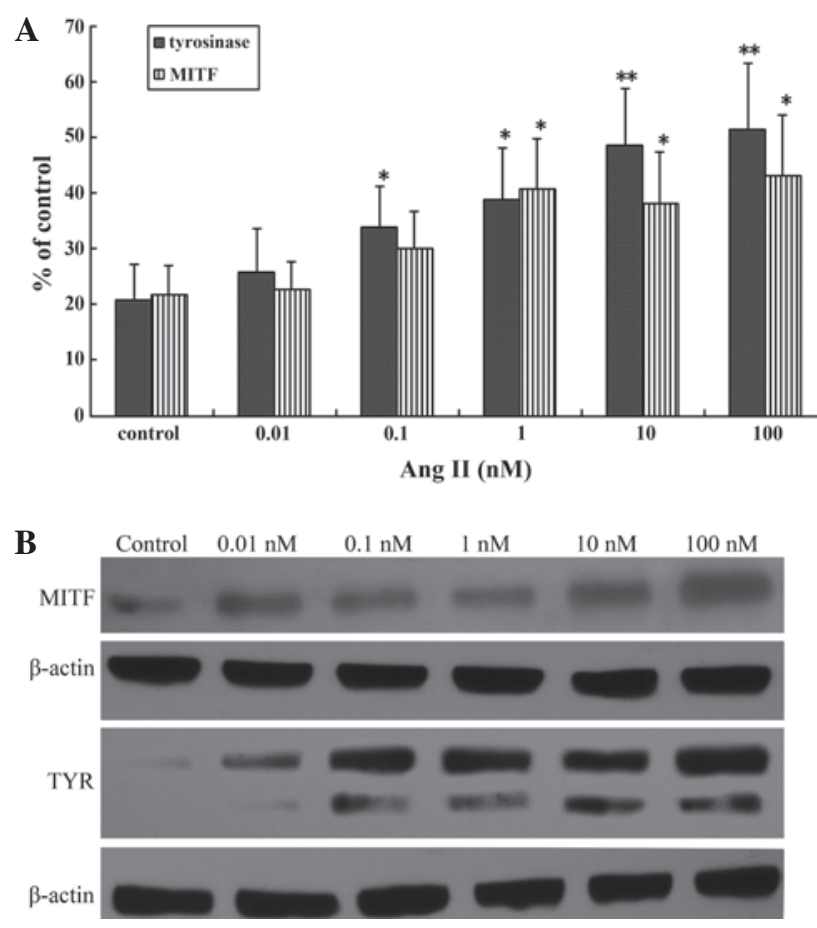

Figure 2. Ang II upregulated MITF and TYR mRNA and protein expression in cultured human melanocytes. (A) Reverse transcription-quantitative polymerase chain reaction analysis of MITF and TYR transcription levels in the presence of different concentrations of Ang II for $24 \mathrm{~h}$. (B) Effect of Ang II on MITF and TYR protein expression in human melanocytes. The presence of different concentrations of Ang II for $24 \mathrm{~h}$ increased MITF and TYR protein expression. Results are expressed as the mean \pm standard error and were confirmed by three independent experiments. ${ }^{*} \mathrm{P}<0.05$ and ${ }^{* *} \mathrm{P}<0.01$ vs. control. MITF, microphthalmia-associated transcription factor; Ang II, angiotensin II; TYR, tyrosinase.

PKC inhibitor inhibits Ang II-induced melanogenesis. Previous studies have reported that PKA and PKC activation stimulates melanogenesis $(27,28)$. Therefore, in the present study, H-89 (a PKA inhibitor) and Ro-32-0432 (a PKC inhibitor) were used to evaluate the molecular mechanisms by which Ang II induces melanogenesis. Melanin content and TYR activity were detected under the combined effect of $100 \mathrm{nM}$ Ang II and $1 \mu \mathrm{M}$ H-89 or Ro-32-0432. Ro-32-0432 completely attenuated the Ang II-induced increases in melanin content and TYR activity while $\mathrm{H}-89$ had no effect on melanin synthesis (Fig. 3A). TYR mRNA and protein expression levels were detected following 

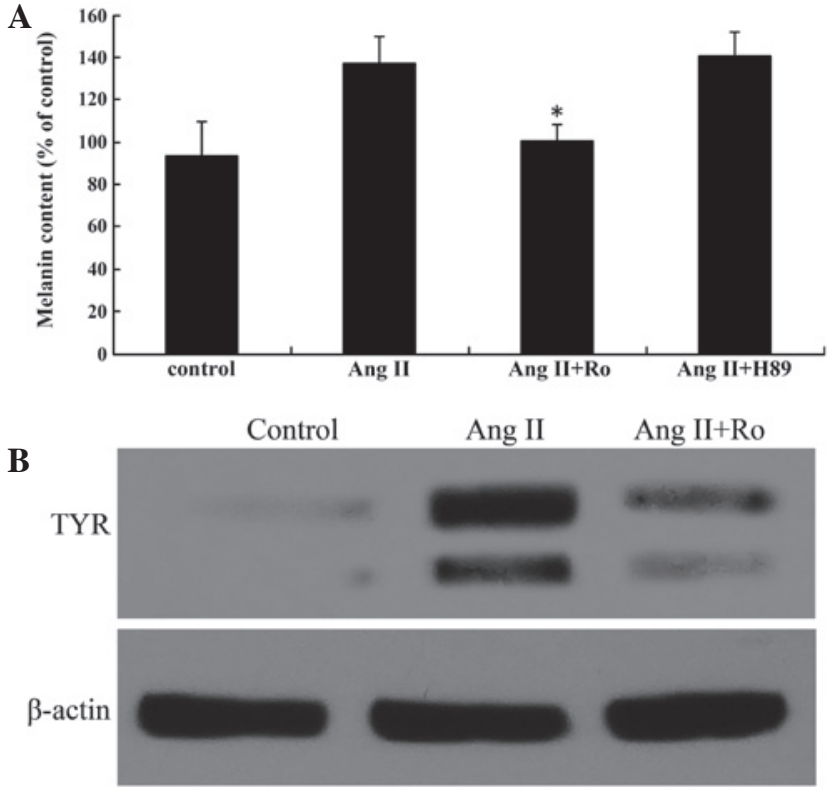

Figure 3. The PKC pathway mediated Ang II-induced stimulation of melanin synthesis. (A) Ang II stimulated melanin content in cultured human melanocytes, while the PKC inhibitor Ro-32-0432 inhibited the effect. (B) Western blot analysis of TYR protein expression in the presence of $100 \mathrm{nM}$ Ang II alone for $24 \mathrm{~h}$ and Ang II combined with Ro for 60 min prior to Ang II stimulation. TYR protein expression was normalized to $\beta$-actin. Results are expressed as the mean \pm standard error and confirmed by three independent experiments. ${ }^{\mathrm{P}}<0.05$ vs. effect of $100 \mathrm{nM}$ Ang II. Ang II, angiotensin II; Ro, Ro-32-0432; TYR, tyrosinase.

the combined treatment with 100 nM Ang II and Ro-32-0432. RT-qPCR and western blot analysis revealed that TYR expression was markedly decreased following the combined Ang II and Ro-32-0432 treatment (Fig. 3B).

\section{Discussion}

The role of Ang II in wound healing has not been fully elucidated; however, previous studies have indicated that Ang II is a potent accelerator of cutaneous wound repair, which certain studies have demonstrated by wounding healing skin $(7,8,29)$. Notably, previous studies have demonstrated significant AT1 receptor expression in primary human melanocytes (12), and found that inhibition of the AT1 receptor limited murine melanoma growth (13). To the best of our knowledge, the present study provides the first indication of the role of Ang II in human melanocyte melanogenesis and elucidates the possible mechanisms involved.

Melanogenesis is controlled by complex regulatory mechanisms, and TYR is the rate-limiting enzyme in melanogenesis. In order to investigate the effect of Ang II on human melanocyte melanogenesis, melanocyte TYR activity and melanin content were evaluated. The results indicate that Ang II significantly increased TYR activity and melanin synthesis, suggesting that Ang II stimulates melanogenesis.

Melanin synthesis is stimulated by numerous effectors, including cAMP- elevating agents, ultraviolet (UV) light, and TYR. The primary transcription factor in the regulation of TYR gene expression is MITF, which serves a crucial function in the regulation of various aspects of melanocyte survival and differentiation (30). Studies suggest that MITF mediates
cAMP-induced increases in the expression of a number of melanogenic proteins $(27,31)$. In order to evaluate the mechanism by which Ang II induces pigmentation, the effects of Ang II on MITF and TYR mRNA and protein expression levels were investigated in human melanocytes. MITF expression was significantly increased following treatment with 100 nM Ang II. RT-qPCR and western blot analysis revealed that Ang II upregulated the expression levels of pigment cell-specific genes, specifically TYR and MITF, in melanocytes, suggesting that Ang II stimulates melanin synthesis by upregulating MITF in melanocytes.

Previous studies of melanin synthesis signaling pathways suggest that the cAMP/PKA and diacylglycerol (DAG)/PKC pathways are involved in melanin synthesis; a number of inextricably linked signaling pathways have been identified (16-18). Previously, research on melanocyte proliferation and melanogenesis signal transduction has focused on the role of cAMP, where the cAMP pathway is a key modulator of melanogenesis. Studies have shown that cAMP-induced increases in the expression of numerous melanogenic proteins are mediated by MITF (27,31). The cAMP pathway upregulates MITF, which is crucial for key melanogenic proteins such as TYR, TYR-related protein-1 (TRP-1) and TRP-2. Notably, Park et al demonstrated that the cAMP pathway also upregulates PKC- $\beta$ expression via MITF (32). In the present study, H-89 (PKA inhibitor) and Ro-32-0432 (PKC inhibitor) were used to evaluate the molecular mechanism by which Ang II induces melanogenesis. It was observed that the PKC inhibitor completely attenuated the Ang II-stimulated increase in melanin content and TYR activity, suggesting that Ang II stimulated melanogenesis via the PKC pathway. The PKC pathway has been identified to be an intracellular signaling pathway that regulates melanogenesis. A previous study observed that adding diacylglycerol, an endogenous PKC activator, to cultured human melanocytes caused a rapid 3-4-fold increase in total melanin content, and that a PKC inhibitor blocked this increase (17). Conversely, topical application of a selective PKC inhibitor reduced pigmentation and blocked UV-induced pigmentation in guinea pig skin (33). In cultured pigment cells, PKC depletion reduced the melanin content markedly $(34,35)$ and blocked $\alpha$-melanocyte-stimulating hormone-induced melanogenesis completely (35). In addition, the results of the present study indicate that $\mathrm{H}-89$ had no effect on melanin synthesis, suggesting that Ang II does not stimulate the PKA pathway in human melanocytes. The present results are consistent with the findings of Mehta and Griendling (21), which were that PKA activation should not occur under Ang II-stimulated conditions. Molnar et al (36) established that PKA is not involved in Ang II-mediated cAMP response-binding element activation in smooth muscle cells, which contradicts a study by Funakoshi et al (37), which reported that PKA was activated in response to Ang II stimulation. Previous studies have also shown that Ang II mediates various cellular functions involving PKC signaling in cardiovascular function and disease (38). Müller et al (39) reported that Ang II inhibits renin gene transcription via the PKC pathway. The results of the present study suggest that the PKC pathway mediates the induction of TYR mRNA and protein expression by Ang II.

In summary, to the best of our knowledge, the present study is the first to demonstrate the effects of Ang II on melanogenesis 
and to identify the molecular mechanisms by which it induces melanogenesis. Specifically, the present results demonstrate that the Ang II-induced pigmentation effect in human melanocytes requires PKC and that the mechanism involves the PKC pathway and MITF upregulation. Collectively, these results may provide a new strategy for the cosmetic study of hyperpigmentation.

\section{Acknowledgements}

The authors thank the native English speaking scientists of Elixigen Corporation for editing this manuscript.

\section{References}

1. Hirobe T: Proliferation of epidermal melanocytes during the healing of skin wounds in newborn mice. J Exp Zool 227: 423-431, 1983.

2. Tobin DJ: The cell biology of human hair follicle pigmentation. Pigment Cell Melanoma Res 24: 75-88, 2011.

3. Nishimura EK: Melanocyte stem cells: A melanocyte reservoir in hair follicles for hair and skin pigmentation. Pigment Cell Melanoma Res 24: 401-410, 2011.

4. Ito M, Liu Y, Yang Z, Nguyen J, Liang F, Morris RJ and Cotsarelis G: Stem cells in the hair follicle bulge contribute to wound repair but not to homeostasis of the epidermis. Nat Med 11: 1351-1354, 2005.

5. McKinney CA, Fattah C, Loughrey CM, Milligan G and Nicklin SA: Angiotensin-(1-7) and angiotensin-(1-9): Function in cardiac and vascular remodelling. Clin Sci (Lond) 126: 815-827, 2014.

6. Ruiz-Ortega M, Lorenzo O, Rupérez M, Esteban V, Suzuki Y, Mezzano S, Plaza JJ and Egido J: Role of the renin-angiotensin system in vascular diseases: Expanding the field. Hypertension 38: $1382-1387,2001$.

7. Takeda H, Katagata Y, Hozumi Y and Kondo S: Effects of angiotensin II receptor signaling during skin wound healing. Am J Pathol 165: 1653-1662, 2004

8. Rodgers K, Abiko M, Girgis W, St Amand K, Campeau J and diZerega G: Acceleration of dermal tissue repair by angiotensin II. Wound Repair Regen 5: 175-183, 1997.

9. Rodgers KE, DeCherney AH, St Amand KM, Dougherty WR, Felix JC, Girgis WW and diZerega GS: Histologic alterations in dermal repair after thermal injury effects of topical angiotensin II. J Burn Care Rehabil 18: 381-388, 1997.

10. Nozawa Y, Matsuura N, Miyake H, Yamada S and Kimura R: Effects of TH-142177 on angiotensin II-induced proliferation, migration and intracellular signaling in vascular smooth muscle cells and on neointimal thickening after balloon injury. Life Sci 64: 2061-2070, 1999.

11. Steckelings UM, Wollschläger T, Peters J, Henz BM, Hermes B and Artuc M: Human skin: Source of and target organ for angiotensin II. Exp Dermatol 13: 148-154, 2004.

12. Steckelings UM, Henz BM, Wiehstutz S, Unger $\mathrm{T}$ and Artuc M: Differential expression of angiotensin receptors in human cutaneous wound healing. Br J Dermatol 153: 887-893, 2005.

13. Otake AH, Mattar AL, Freitas HC, Machado CM, Nonogaki S, Fujihara CK, Zatz R and Chammas R: Inhibition of angiotensin II receptor 1 limits tumor-associated angiogenesis and attenuates growth of murine melanoma. Cancer Chemother Pharmacol 66: 79-87, 2010.

14. Widlund HR and Fisher DE: Microphthalamia-associated transcription factor: A critical regulator of pigment cell development and survival. Oncogene 22: 3035-3041, 2003.

15. Lee AY and Noh M: The regulation of epidermal melanogenesis via cAMP and/or PKC signaling pathways: Insights for the development of hypopigmenting agents. Arch Pharm Res 36: 792-801, 2013.

16. Buscà R and Ballotti R: Cyclic AMP a key messenger in the regulation of skin pigmentation. Pigment Cell Res 13: 60-69, 2000.

17. Gordon PR and Gilchrest BA: Human melanogenesis is stimulated by diacylglycerol. J Invest Dermatol 93: 700-702, 1989.
18. Park HY and Gilchrest BA: Signaling pathways mediating melanogenesis. Cell Mol Biol (Noisy-le-grand) 45: 919-930, 1999.

19. Leite-Moreira AF, Castro-Chaves P, Pimentel-Nunes P, Lima-Carneiro A, Guerra MS, Soares JB and Ferreira-Martins J: Angiotensin II acutely decreases myocardial stiffness: A novel AT1, PKC and $\mathrm{Na}^{+} / \mathrm{H}^{+}$exchanger-mediated effect. Br J Pharmacol 147: 690-697, 2006.

20. Berthold H, Just A, Kirchheim HR and Ehmke H: Interaction between nitric oxide and endogenous vasoconstrictors in control of renal blood flow. Hypertension 34: 1254-1258, 1999.

21. Mehta PK and Griendling KK: Angiotensin II cell signaling: Physiological and pathological effects in the cardiovascular system. Am J Physiol Cell Physiol 292: C82-C97, 2007.

22. Lei TC, Virador VM, Vieira WD and Hearing VJ: A melanocyte-keratinocyte coculture model to assess regulators of pigmentation in vitro. Anal Biochem 305: 260-268, 2002.

23. Virador VM, Kobayashi N, Matsunaga J and Hearing VJ: A standardized protocol for assessing regulators of pigmentation. Anal Biochem 270: 207-219, 1999.

24. Marin-Castaño ME, Elliot SJ, Potier M, Karl M, Striker LJ, Striker GE, Csaky KG and Cousins SW: Regulation of estrogen receptors and MMP-2 expression by estrogens in human retinal pigment epithelium. Invest Ophthalmol Vis Sci 44: 50-59, 2003.

25. Aksan I and Goding CR: Targeting the microphthalmia basic helix-loop-helix-leucine zipper transcription factor to a subset of E-box elements in vitro and in vivo. Mol Cell Biol 18: 6930-6938, 1998.

26. Halaban R, Pomerantz SH, Marshall S, Lambert DT and Lerner AB: Regulation of tyrosinase in human melanocytes grown in culture. J Cell Biol 97: 480-488, 1983.

27. Bertolotto C, Abbe P, Hemesath TJ, Bille K, Fisher DE, Ortonne JP and Ballotti R: Microphthalmia gene product as a signal transducer in cAMP-induced differentiation of melanocytes. J Cell Biol 142: 827-835, 1998.

28. Price ER, Horstmann MA, Wells AG, Weilbaecher KN, Takemoto CM, Landis MW and Fisher DE: alpha-Melanocyte-stimulating hormone signaling regulates expression of microphthalmia, a gene deficient in Waardenburg syndrome. J Biol Chem 273: 33042-33047, 1998.

29. Steckelings UM, Artuc M, Paul M, Stoll M and Henz BM: Angiotensin II stimulates proliferation of primary human keratinocytes via a non-AT1, non-AT2 angiotensin receptor. Biochem Biophys Res Commun 229: 329-333, 1996.

30. Gaggioli C, Buscà R, Abbe P, Ortonne JP and Ballotti R: Microphthalmia-associated transcription factor (MITF) is required but is not sufficient to induce the expression of melanogenic genes. Pigment Cell Res 16: 374-382, 2003.

31. Shibahara S, Takeda K, Yasumoto K, Udono T, Watanabe K, Saito $\mathrm{H}$ and Takahashi K: Microphthalmia-associated transcription factor (MITF): Multiplicity in structure, function, and regulation. J Investig Dermatol Symp Proc 6: 99-104, 2001.

32. Park HY, Wu C, Yonemoto L, Murphy-Smith M, Wu H, Stachur CM and Gilchrest BA: MITF mediates cAMP-induced protein kinase C-beta expression in human melanocytes. Biochem J 395: 571-578, 2006.

33. Park HY, Lee J, González S, Middelkamp-Hup MA, Kapasi S, Peterson S and Gilchrest BA: Topical application of a protein kinase $\mathrm{C}$ inhibitor reduces skin and hair pigmentation. $\mathrm{J}$ Invest Dermatol 122: 159-166, 2004.

34. Niles RM and Loewy BP: Induction of protein kinase $C$ in mouse melanoma cells by retinoic acid. Cancer Res 49: 4483-4487, 1989.

35. Park HY, Russakovsky V, Ao Y, Fernandez E and Gilchrest BA: Alpha-melanocyte stimulating hormone-induced pigmentation is blocked by depletion of protein kinase C. Exp Cell Res 227: 70-79, 1996.

36. Molnar P, Perrault R, Louis S and Zahradka P: The cyclic AMP response element-binding protein (CREB) mediates smooth muscle cell proliferation in response to angiotensin II. J Cell Commun Signal 8: 29-37, 2014.

37. Funakoshi Y, Ichiki T, Takeda $\mathrm{K}$, Tokuno $\mathrm{T}$, Iino $\mathrm{N}$ and Takeshita A: Critical role of cAMP-response element-binding protein for angiotensin II-induced hypertrophy of vascular smooth muscle cells. J Biol Chem 277: 18710-18717, 2002.

38. Chintalgattu V and Katwa LC: Role of protein kinase C-delta in angiotensin II induced cardiac fibrosis. Biochem Biophys Res Commun 386: 612-616, 2009.

39. Müller MW, Todorov V, Krämer BK and Kurtz A: Angiotensin II inhibits renin gene transcription via the protein kinase $\mathrm{C}$ pathway. Pflugers Arch 444: 499-505, 2002. 